REVIEW SERIES

\title{
Lung cancer - 9: Molecular biology of lung cancer: clinical implications
}

\author{
K M Fong, Y Sekido, A F Gazdar, J D Minna
}

Thorax 2003;58:892-900

It has been hypothesised that clinically evident lung cancers have accumulated many different genetic or epigenetic abnormalities in oncogenes and/or tumour suppressor genes. This notion has important clinical ramifications. Recent developments in our knowledge of the molecular biology of lung cancer are reviewed, with particular reference to genetic abnormalities in tumour suppressor gene inactivation and overactivity of growth promoting oncogenes. These changes lead to the "hallmarks of lung cancer". These hallmarks are the new rational targets for early detection, prevention, and treatment of lung cancer.

See end of article for authors' affiliations

Correspondence to:

Dr J D Minna, Hamon Center for Therapeutic Oncology Research NB8.206, University of Texas Southwestern Medical Center, 6000 Harry Hines Blvd, Dallas, TX 75390-8593, USA;

John.Minna@

UTSouthwestern.edu
$\mathrm{T}$ he advances in molecular technologies are providing insight into the pathobiology of lung cancer development. It is becoming apparent through candidate gene and genome wide approaches that clinically evident lung cancers have accumulated numerous (perhaps 20 or more) clonal genetic and epigenetic alterations as a multistep process. These alterations include the classical genetic abnormalities of tumour suppressor gene (TSG) inactivation and overactivity of growth promoting oncogenes. More recently, tumour acquired promoter hypermethylation has been recognised as a mechanism for the epigenetic inactivation of gene expression. The early clonal genetic lesions that occur in smoking damaged preneoplastic bronchial epithelium are being identified, as are the molecular differences between small cell lung cancer (SCLC) and non-small cell lung cancer (NSCLC), and between tumours with different clinical outcomes. These abnormalities lead to the "hallmarks of lung cancer". Molecular studies are now performed in many research laboratories in an integrated approach with clinical investigators. These will lead to clinical applications with the potential to provide new avenues for early diagnosis, risk assessment, prevention, and treatment for this common and highly lethal condition. ${ }^{12}$

\section{SPECTRUM OF MOLECULAR ALTERATIONS RESULTS IN THE HALLMARKS OF LUNG CANCER}

Recent molecular developments are increasing our knowledge of the changes somatically acquired by lung cancer cells during their pathogenesis..$^{3-6}$ Much more is known about the molecular abnormalities that occur in clinically overt lung cancers, which are more easily studied than in the small number of preneoplastic cells in smoking damaged respiratory epithelium which require special study methods. Nonetheless, such techniques as precise laser capture microdissection now allow the molecular testing of minute specimens and can reveal DNA lesions as well as aberrant gene expression to complement traditional methods such as immunohistochemistry. At the other end of the spectrum, gene microarrays are making it possible to study the expression of thousands of genes in individual lung cancers, with initial studies showing that it is possible to reproducibly classify lung cancers into relevant histological and clinical prognostic groups based on their gene expression profiles. ${ }^{78}$ Such advances bode well for learning more about the biology of lung cancers and, to the clinician, the potential also to provide novel predictive information on tumour behaviour, survival, and response to treatment.

Smoking is the major cause of most cases of lung cancer and is the result of nicotine addiction and cigarette smoke carcinogens (reviewed in Hecht ${ }^{9}$ ). Our major efforts must therefore continue to be preventing smoking initiation and helping with smoking cessation through a variety of methods..$^{10}$ Nevertheless, recent molecular studies show that genetic damage to the smoking exposed respiratory epithelium persists for decades after smoking cessation, and in the USA about $50 \%$ of all lung cancers currently occur in former cigarette smokers; we will therefore need to deal with the possibility that lung cancer can develop even after smoking cessation. ${ }^{911}$ It is likely that lung cancer cells start to harbour genetic damage after prolonged exposure to tobacco smoke, with changes demonstrable in morphologically normal cells from smokers. ${ }^{11-14}$ It appears that genetic damage continues to accumulate in bronchial epithelial cells in line with traditional indices of increasing preneoplastic morphology. Ultimately, multiple clonal lesions are detectable in overt invasive lung cancers, and perhaps even more in metastatic lesions, consistent with the multistep model of carcinogenesis. The genetic and cellular targets of the carcinogenic process are notably diverse, yielding the following "hallmarks of cancer" $^{\prime \prime 15}$ :

- abnormalities in self-sufficiency of growth signals;

- evading apoptosis;

- insensitivity to anti-growth signals;

- limitless replicative potential;

- sustained angiogenesis; and 
- tissue invasion and metastases.

Abnormalities in DNA repair and a genetic predisposition to develop lung cancer, particularly with exposure to smoking, sets the stage for the development of this carcinogenic process.

\section{Self-sufficiency of growth signals: proto-oncogenes and growth stimulation by autocrine and paracrine factors}

A number of growth factors and their cognate receptors are expressed by lung cancers or their adjacent stromal cells, thus producing autocrine and paracrine growth stimulation loops. Several are encoded for by proto-oncogenes which become activated in the course of lung cancer development. ${ }^{4-6}$ The ERBB family is a group of transmembrane receptor tyrosine kinases which, together with their ligands, constitutes a potential growth stimulatory loop, particularly for NSCLCs. The two members important for lung cancer are the epidermal growth factor receptor (EGFR, ERBBl) and HER2/neu (ERBB2), which are expressed independently of one another in NSCLC. ${ }^{16}$ On ligand binding, ERBB receptors homodimerise or heterodimerise, thereby inducing intrinsic kinase activities that initiate intracellular signal transduction cascades including the MAP kinases. EGFR regulates epithelial proliferation and differentiation and can be overexpressed in lung cancers. Moreover, lung cancer cells also express ligands for EGFR such as epidermal growth factor (EGF) and transforming growth factor $\alpha(\mathrm{TGF} \alpha)$, thereby producing a potential autocrine growth loop. ${ }^{17-19}$ Some, but not all, studies have associated EGFR expression with impaired survival. ${ }^{16}{ }^{20-24}$ Monoclonal antibodies against the EGFR (C225, ImClone) are entering clinical trials in combination with chemotherapy. ${ }^{25}$ In addition, tyrosine kinase inhibitors that have some selectivity such as ERBBl blockers (CP358774, ZD1839-Iressa, OSI774) are also being tested, most with the advantage of being orally active. Another ERBB family member, HER2/neu, is highly expressed in about $30 \%$ of NSCLCs, especially adenocarcinomas. ${ }^{18} 26$ High HER2/neu levels are associated with the multiple drug resistance phenotype ${ }^{27}$ and increased metastatic potential in NSCLC, ${ }^{28}$ which may help to explain the poor clinical outcome linked to HER2/neu overexpression reported by some but not all investigators. ${ }^{16222429}$ Clinical trials investigating chemotherapy combined with trastuzumab (Herceptin), a monoclonal antibody against the HER2/ neu receptor, are in progress in lung cancer. ${ }^{30}$

The autocrine loop comprising stem cell factor and its tyrosine kinase receptor CDI17 is activated in some lung cancers-more often in SCLC than NSCLC-with resultant growth promotion or chemoattraction. The recent development of specific tyrosine kinase inhibitors to target this pathway may translate into novel approaches for this highly lethal subtype. ${ }^{31-33}$ Similarly, the gastrin releasing peptide (GRP) growth stimulatory loop is involved in $20-60 \%$ of SCLCs. ${ }^{34}$ The therapeutic potential of inhibiting this pathway with a neutralising monoclonal antibody directed against GRP, as well as by antagonists of GRP (also referred to as bombesin), is being tested in early clinical trials of SCLC. ${ }^{35} 36$ The GRP receptors belong to a G-protein coupled receptor superfamily including GRP-, neuromedin B- and bombesin subtype-3 receptors; all of these can be expressed in lung cancers of all histological types and some bronchial epithelial biopsies from smokers, implying an early pathogenic role for this family. ${ }^{37} 38$ The GRP receptor is expressed more frequently in women (where there are two expressed copies of the $\mathrm{X}$ linked gene) than in men in the absence of smoking. Its expression is activated earlier in women in response to tobacco exposure, which may be a factor in the increased susceptibility of women to tobacco induced lung cancer. ${ }^{39}$ Other putative growth factor systems include insulin-like growth factors (IGF) I and II, the type I IGF receptor, platelet derived growth factor/receptor, and the hepatocyte growth factor/receptor. ${ }^{50}$ Each of these should be further studied for any potential clinical usefulness. Insulin-like growth factor binding protein-6 (IGFBP-6) activated programmed cell death in NSCLC cells while IGFBP-3 inhibited cell growth in human lung cancers, suggesting that these binding proteins might potentially be new treatments. ${ }^{41}{ }^{42}$ In addition, high levels of blood IGF-I and enhanced mutagen sensitivity of peripheral blood lymphocytes were individually associated with an increased risk of lung cancer, which suggests that genetic polymorphisms in IGFs may predispose to the development of lung cancer. ${ }^{43}$

The RAS proto-oncogene family (KRAS, HRAS, and NRAS) which encodes $21 \mathrm{kD}$ plasma membrane proteins comprises an important signal transduction pathway. Its members, especially KRAS, can be activated in some lung cancers by point mutations, leading to inappropriate signalling for cell proliferation. The KRAS gene is frequently mutated at codon 12 and also at codons 13 and 61. Mutations are found in 15$20 \%$ of all NSCLCs apart from SCLCs, especially adenocarcinomas (20-30\%). ${ }^{34}$ KRAS mutations correlate with smoking, ${ }^{44}$ often being the G-T transversions associated with polycyclic hydrocarbons and nitrosamines. ${ }^{45}$ In mice, somatic activation of KRAS by spontaneous recombination predisposes the animals to tumours, predominantly early onset lung cancer. ${ }^{46}$ While the prognostic importance of KRAS mutations is debated, ${ }^{47-51}$ it does not appear to predict the response to chemotherapy. ${ }^{52}$ Two recent large studies in resected NSCLC showed that KRAS mutations were independent but weak predictors of survival. ${ }^{53} 54$ The necessity for the Ras protein to undergo farnesylation to become active has led to the development of specific inhibitors of the responsible farnesyltransferase enzyme. Several of these agents are currently in clinical trials against lung cancer (for example, BMS214662, RII5777, SCH 66336), and trials of vaccination with mutant KRAS peptides are also underway. ${ }^{55}$ Other potential avenues to block RAS include antisense treatment, inhibition of protein expression, or downstream effectors. ${ }^{56}$

The MYC proto-oncogene family encodes nuclear products which are the ultimate target of RAS signal transduction; the most frequently involved family member is C-MYC in both SCLC and NSCLC, unlike MYCN and MYCL which are generally activated only in SCLC. Activation occurs as a result of protein overexpression caused by gene amplification or by transcriptional dysregulation. There also appears to be a change in lung cancers leading to increased stability of MYC mRNA. ${ }^{57}$ Approximately $18-31 \%$ of SCLCs had amplification of one MYC family member compared with $8-20 \%$ of NSCLCs. $^{34}$ MYC amplification appears to occur more frequently in chemotherapy treated patients, and the "variant" SCLC subtype may correlate with adverse survival. Recent studies have suggested that low levels of MYC amplification occur in NSCLC and are associated with impaired survival; the combination of MYC expression with loss of caspase- 3 (an apoptosis inducer) expression results in worse survival. $^{5859}$ MYC expression may represent an avenue for therapeutic manipulation. For instance, the growth inhibition of an SCLC cell line by all-trans-retinoic acid appears to be associated with increased MYCL and decreased MYC expression. ${ }^{60}$ Moreover, antisense therapy strategies directed at downregulating MYC expression appear encouraging in cell culture systems.

\section{Evading apoptosis}

Tumour cells often escape the normal physiological response (termed programmed cell death or apoptosis) when challenged 
by cellular and DNA damage. Key players include the p53 gene and the BCL2 proto-oncogene. BCL2 protects against apoptosis and its expression is higher in SCLC (75-95\%) than in NSCLC. These findings are seemingly unexpected as SCLCs are more sensitive to chemotherapy, which often induces an apoptotic response. In any case, the prognostic value of BCL2 expression is controversial. ${ }^{56}$ BCL2 expression in tumours actually predicts increased survival of patients with NSCLC. ${ }^{62}$ BAX is a BCL2 related protein which promotes apoptosis and is a downstream transcription target of p53. BAX and BCL2 expression is inversely related in neuroendocrine cancers; high BCL2 and low BAX expression occurs in most SCLCs which are usually p53 deficient. ${ }^{63}$ Expression of the inhibitor of apoptosis protein (IAP)- 1 acts as an important anti-apoptotic protein mediating sensitivity to deoxynucleotide analogues in NSCLC cells. ${ }^{64}$ Among the anti-apoptosis strategies in preclinical trials are studies of antisense BCL2 in SCLC (to downregulate BCL2 protein expression), BCL-XL antisense in NSCLC, and a bispecific BCL2-BCLXL antisense to target both SCLC and NSCLC.

\section{Insensitivity to anti-growth signals: tumour suppressor genes (TSGs)}

TSGs play a critical role in controlling normal cell growth. They generally inhibit the tumorigenic process but can also be involved in the response and repair of DNA damage. TSGs are rendered inactive by chromosomal loss of one allele (loss of heterozygosity $(\mathrm{LOH})$ ) and damage to the other by genetic mutation or the epigenetic hypermethylation of its promoter. Studies of LOH as a marker of TSG inactivation have shown that a number of chromosomal regions are damaged in overt lung cancer cells. For instance, a genome wide search for LOH in 36 lung cancer cell lines using $\sim 400$ high resolution polymorphic markers showed that tumours had a mean of 17-22 "hot spots" of chromosomal loss. ${ }^{65}$ There were 22 different regions with more than $60 \% \mathrm{LOH}, 13$ with a preference for SCLC, seven for NSCLC, and two affecting both histological types. The sharing of some $\mathrm{LOH}$ regions and the specificity of others may provide an insight into the genes common to lung cancer development and others specific to subtype differentiation. The chromosomal arms with the most frequent LOH were $1 p, 3 p, 4 p, 4 q, 5 q, 8 p, 9 p$ (pl6 TSG locus), 9q, 10p, 10q, 13q (RB-retinoblastoma TSG locus), 15q, 17p (p53 TSG locus), 18q, 19p, Xp, and Xq.

There is an intense hunt for the candidate genes in chromosomal regions with high frequencies of $\mathrm{LOH}$ where the precise TSG is not known. For example, several candidate genes are located on $3 p$ where $\mathrm{LOH}$ can be found in up to $96 \%$ of lung cancers and $78 \%$ of preneoplastic/preinvasive lesions, ${ }^{66}$ as well as by homozygous deletions. ${ }^{5}$ The frequency and size of $3 p$ LOH increased with the severity of histopathological preneoplastic/preinvasive changes. One candidate TSG is FHIT at the 3pl4.2 region; lung cancer cells frequently express abnormal mRNA transcripts of FHIT apart from normal wild type transcripts. ${ }^{67}{ }^{68}$ Re-introduction of exogenous FHIT may suppress the tumorigenicity of a lung cancer cell line in nude mice. ${ }^{6970}$ There are also TSG candidates at the $3 \mathrm{p} 21.3$ region which appear to suppress the tumorigenic phenotype when introduced back into lung cancers with numerous other genetic lesions. ${ }^{71}$ One such is the RASSF1A mRNA isoform at the RASSF1 locus ${ }^{72-74}$; while the gene is rarely mutated, its expression is lost by promoter acquired hypermethylation in $\sim 90 \%$ of SCLCs and $30-40 \%$ of NSCLCs. Methylation in NSCLCs is associated with adverse survival, and treatment of lung cancer cells with 5-aza-2' deoxycytidine reactivates RASSFIA expression. RASSFIA acts to inhibit DNA synthesis and downregulate the expression of cyclin Dl at a post-transcriptional level. Also located in the $3 \mathrm{p} 21$ region with $5 \mathrm{~kb}$ and $50 \mathrm{~kb}$, respectively, are the
FUS1 and SEMA3B genes. ${ }^{71} 7576$ Expression of wild type but not tumour acquired mutant FUSI dramatically suppresses the growth in vitro of lung cancer cells, while systemic delivery of FUS1 in an adenovirus vector resulted in regression of metastatic disease in a lung cancer mouse xenograft model. ${ }^{76}$ Wild type SEMA3B reintroduced into lung cancer cells induces apoptosis, unlike SEMA3B missense mutants. ${ }^{77}$ In addition, transfection of SEMA3B into cells results in conditioned media that induce the death of lung cancer cells, which raises the possibility of using this soluble secreted protein as a systemic anticancer treatment. ${ }^{77}$ Other $3 p$ genes with evidence of tumour suppressor activity are DUTTl/ROBOl, which was associated with inadequate lung development and bronchial hyperplasia in mice with a targeted deletion of the gene, ${ }^{78}$ and retinoic acid receptor (RAR) $\beta$ which frequently undergoes $\mathrm{LOH}$ and promoter hypermethylation. ${ }^{79}$ There are therefore a number of candidate $3 p$ TSGs, and LOH here may possibly be the earliest acquired genetic change in lung cancer development

Other chromosomal regions affected by $\mathrm{LOH}$ in lung cancers house known TSGs such as p53, retinoblastoma $(\mathrm{RB})$, and pl6, and these are often found to be abnormal by immunohistochemical examination in lung cancer. ${ }^{80}$ p53 is a key TSG; its protein helps maintain genomic integrity in the face of DNA damage from $\gamma$ or UV irradiation and carcinogens. DNA damage or hypoxia upregulates p53 which acts as a transcription factor regulating a number of downstream genes including p21, MDM2, GADD45, and BAX, thereby helping to regulate the $\mathrm{Gl} / \mathrm{S}$ cell cycle transition, G2/M DNA damage check point, and apoptosis. p53 inactivation occurs in $\geqslant 75 \%$ of SCLCs and about $50 \%$ of NSCLCs, ${ }^{45} 5354$ 81-83 with mutations correlating with cigarette smoking and comprising the G-T transversions expected of tobacco smoke carcinogens. Missense p53 mutations can prolong the protein half life leading to easily detected mutant p53 protein by immunohistochemistry. ${ }^{53} 5483$ p53 mutations have been linked to response to cis-platinum based chemotherapy in $\mathrm{NSCLC}^{84}$ and the response to radiotherapy. ${ }^{85}$ While there is debate on the prognostic role of p53 abnormalities in NSCLC, the preponderance of evidence suggests that the presence of such abnormalities leads to a worse prognosis. ${ }^{53548386}$ p53 is a prototypic model for gene replacement therapy in lung cancer. Preclinical studies showed that restoring p53 function resulted in apoptosis of cancer cells, and have progressed to phase II clinical trials where adenoviral mediated p53 gene transfer delivered by direct tumour injection appeared feasible when given in conjunction with radiation therapy.$^{87}$ Conversely, intratumoral injection of adenoviral p53 appeared to provide no additional benefit in patients receiving first line chemotherapy for advanced NSCLC. ${ }^{88}$ Vaccine trials with mutant p53 peptides are also being performed. p53 is kept at virtually undetectable levels in normal cells by an autoregulatory loop involving the production of HDM2, the human homologue of the murine double minute 2 (MDM2) oncogene which blocks p53 regulation of target genes and enhances its proteasome dependent degradation. Conversely, p53 regulates (increases) the expression of HDM2 by directly binding and activating the HDM2 promoter, thereby downregulating itself. The HDM2 protein is overexpressed in $25 \%$ of NSCLCs, ${ }^{89}$ thus representing another way of abrogating p53 function. HDM2, in turn, is inactivated by pl4ARF, the alternative product of the pl6 gene whose downregulation is similarly associated with loss of $\mathrm{p} 53 / \mathrm{HDM} 2 / \mathrm{pl}$ ARF pathway function.

p16 is part of the p16-cyclin D1-CDK4-RB pathway that is central to controlling the Gl-S transition of the cell cycle. This critical cell cycle regulatory pathway is functionally altered or mutated in many cancers including those of lung origin. Each member of the pathway may be rendered 
dysfunctional during carcinogenesis. Functional loss of the RB gene can include deletions, nonsense mutations, or splicing abnormalities leading to protein abnormalities in most SCLCs and 15-30\% of NSCLCs. ${ }^{80}{ }^{90-92}$ Functionally, in vitro re-introduction into tumour cells of a wild type RB suppresses SCLC growth. ${ }^{93}$ Whereas in SCLC the pathway is usually disrupted by RB gene inactivation, cyclin D1, CDK4 and especially pl6 abnormalities are common in NSCLC. Cyclin Dl inhibits the activity of $\mathrm{RB}$ by stimulating its phosphorylation by cyclin dependent kinase 4 (CDK4). Thus, cyclin Dl overexpression is an alternative mechanism for abrogating this pathway and is found in $25-47 \%$ of NSCLC, possibly with a role as a predictor of poor prognosis. ${ }^{94} 95$ Furthermore, transfection of a cyclin Dl antisense construct into lung cancer cell lines can be shown to destabilise RB and retard growth. ${ }^{96}$ CDK4 expression has also been reported in $\mathrm{NSCLCs}^{97}$ and an example of potential therapeutic manipulation is flavopiridol. This compound, which inhibits cyclin dependent kinase, is being tested in clinical trials. ${ }^{98}$ pl6 regulates RB function by inhibiting CDK4 and CDK6 kinase activity. pl6 (or CDKN2) is situated on the short arm of chromosome 9 at region 21 and undergoes heterozygous and homozygous loss, mutation, and aberrant promoter hypermethylation in lung cancer, ultimately inactivating its function. ${ }^{3}$ Perhaps $30-50 \%$ of early stage primary NSCLCs do not express p16. The pl6 locus also encodes a second alternative reading frame protein, pl4ARF, which functions in the p53/HDM2/p14ARF pathway as discussed above. Interestingly, as an example of their evolutionary deviousness, lung tumours have developed distinct ways of interfering with the two different products from a single genetic locus, each of which functions in a distinct growth regulatory pathway. Moreover, the specific mutational targets differ according to lung cancer subtype, indicating the need for efforts to better understand their relative contribution to tumour differentiation. ${ }^{61}$

\section{Tumour acquired promoter hypermethylation as a} method of inactivating the expression of TSGs

Tumour acquired promoter methylation is increasingly recognised as an important epigenetic mechanism for inactivating genes. We and others have found tumour acquired aberrant promoter methylation in a number of genes including RAR $\beta$, TIMP-3, pl6, MGMT, FHIT, DAPK, $E C A D, p 14 A R F$, and GSTP1. ${ }^{79-101}$ At least one gene was methylated in most resected primary NSCLCs, while normal control lung tissue from the same patients was only rarely methylated. About 13\% of the NSCLCs exhibited more frequent promoter hypermethylation, suggesting a "global CpG island methylator phenotype". In NSCLCs hypermethylation contributes to downregulation of pl6 expression; it occurs at an early stage in lung carcinogenesis ${ }^{102-104}$ and correlates with smoking. ${ }^{105}$ Other regional sites of hypermethylation have been found in lung cancer, including sites at 3p (RARß, FHIT, RASSFIA, SEMA3B), 4q34, 10q26, and $17 \mathrm{pl3}$, although the precise gene targets at several of these sites are uncertain and the significance is not yet apparent. ${ }^{106} 107$ Hypermethylation of certain gene promoters may also have relevance in predicting the clinical outcome for lung cancer patients. ${ }^{74}{ }^{105}$ As methylated DNA sequences can be found even in the setting of a high background of constitutionally unmethylated normal DNA, they are attractive candidates for early molecular detection tools and for following chemoprevention studies. ${ }^{108}$ For instance, one group detected aberrant hypermethylation of $p 16$ and/or 06 MGMT genes in DNA from sputum of patients with squamous cell lung cancer up to 3 years before clinical diagnosis. ${ }^{109}$ In addition, abnormal identically methylated DNA can be detected in serum from patients where the tumour was methylated. ${ }^{110}$ Apart from potential diagnostic usefulness, the ability for hypermethylation to be reversed with drugs could lead to therapeutic developments. ${ }^{111}$ For instance, retinoic acid plays an important role in lung development and differentiation, acting primarily via nuclear receptors encoded by the retinoic acid receptor- $\beta$ (RARB) gene. RARB is often hypermethylated in lung cancers, particularly SCLC, ${ }^{79}$ and chemical demethylation may provide an avenue for the re-expression of $R A R B$.

\section{Limitless replicative potential: telomerase}

Telomerase is the enzyme that adds hexameric TTAGGG nucleotide repeats onto the ends (telomers) of chromosomal DNAs to compensate for losses that occur with each round of DNA replication. Normal somatic cells do not have telomerase activity and stop dividing when the telomeric ends of at least some chromosomes have been shortened to a critical length. Immortalised cells, including nearly all lung cancers, probably continue to proliferate indefinitely because they express telomerase. ${ }^{112-114}$ While activation of telomerase is not the earliest step in the pathogenesis of lung cancer, it does occur early enough to be a potential molecular marker that can be detected in preneoplastic cells of the bronchial epithelium and in bronchial lavage specimens. ${ }^{115} 116$ Because all lung cancers express telomerase, studies of the level of expression in individual tumours will need to be correlated with prognosis and appear to correlate with the presence of lymph node metastases. ${ }^{117}$ Besides its use as a diagnostic tool, drugs targeting telomerase have therapeutic potential. Several of these involving anti-sense approaches are nearing entry into clinical trials. ${ }^{118}$

\section{Sustained angiogenesis}

Lung cancers engender angiogenesis, and the expression of a large number of tumour blood vessels as manifest by tumour microvascularity counts is generally associated with a poor prognosis, although there are some dissenting opinions. ${ }^{119-122}$ There are several isoforms of vascular endothelial growth factor (VEGF). The expression ratio of the VEGF189 mRNA isoform had a greater correlation with tumour angiogenesis, postoperative relapse time, and survival than those for the VEGF121, VEGF165, and VEGF206 mRNA isoforms, which suggests that it could be used as a prognostic indicator for patients with NSCLC. ${ }^{123}$ This increase in tumour neovasculature arises largely because of production of VEGF by lung cancer cells. ${ }^{124-126}$ Part of this dysregulation may arise through loss of p53 function. ${ }^{126}{ }^{127}$ Clinically, plasma VEGF levels can predict the degree of angiogenesis in NSCLC. ${ }^{128}$ Some impressive results have recently been presented in abstract form from clinical trials targeting VEGF with a humanised monoclonal anti-VEGF antibody. These initial trials were fraught with toxicity related to unexpected bleeding from large necrotic lung tumour masses, but this should be approachable by patient selection.

\section{Tissue invasion and metastases}

Many of the changes discussed above lead to the ability of lung cancer cells to invade into tissues and to spread and survive in metastatic deposits. ${ }^{54}{ }^{129}$ One of the interesting new candidates to participate in invasion and metastasis is CRMP1 , a protein involved in mediating the effect of collapsins. ${ }^{130}$ Lung cancer specimens showed that reduced expression of CRMP-1 is associated with advanced disease, lymph node metastasis, early postoperative relapse, and shorter survival, indicating that CRMP-1 is involved in cancer invasion and metastasis. ${ }^{130}$ Collapsins are part of the semaphorin family, so CRMP-1 may provide another indication of the role of semaphorins and the pathways they mediate in the pathogenesis of lung cancer. Laminins and integrins are being intensively studied as key markers of tissue invasion through 
the basement membrane and subsequent development of metastases. The expression of laminin $\alpha$ chains ( $\alpha 3$ and $\alpha 5$ ) is often reduced in lung cancer cells; this might contribute to basement membrane fragmentation and subsequent proliferation of stromal elements, as well as having a role in the process of cancer cell invasion. ${ }^{131}$ The $L A M B 3$ gene (encoding the laminin $\beta 3$ chain, a unique component of laminin-5) was expressed in NSCLC cells and not in SCLC cells. ${ }^{132}$ Laminin-5 is a heterotrimeric protein consisting of the $\alpha 3, \beta 3$, and $\gamma 2$ chains, and another unique component of laminin-5, the $\gamma 2$ chain encoded by the $L A M C 2$ gene. Since $\alpha 6 \beta 4$-integrin, the specific laminin-5 binding receptor, is known to be expressed only in NSCLCs and not in SCLCs, it appears that laminin-5 is a critical microenvironmental factor for the growth of NSCLC but not of SCLC cells. ${ }^{132}$ Survival analysis revealed that overexpression of laminin-5 was associated with shorter patient survival and was an independent prognostic factor in NSCLC. ${ }^{133}$

\section{GENETIC PREDISPOSITION TO DEVELOPING LUNG CANCER: MOLECULAR EPIDEMIOLOGY}

From studies in twins it is clear that there are genetic factors related to smoking initiation and persistence. ${ }^{134}{ }^{135}$ One of the major components of this is therefore nicotine addiction, and a major new field of research is the identification of genetic factors and polymorphisms that predispose to nicotine addiction. Possible associated genes include cytochrome P450 subfamily polypeptide 6 (CYP2A6), dopamine D(1), $\mathrm{D}(2)$, and $\mathrm{D}(4)$ receptors, dopamine transporter, and serotonin transporter genes. ${ }^{136}$ Approximately $11 \%$ of tobacco smokers ultimately develop lung cancer, which suggests that genetic factors may influence the risk for lung cancer among those who are exposed to carcinogens. ${ }^{137}$ Epidemiological studies show an approximatelyl4-fold increased risk for lung cancer among average tobacco smokers and a 2.5-fold increased risk attributable to a family history of lung cancer after controlling for tobacco smoke. ${ }^{137}$ While a rare autosomal dominant gene may explain susceptibility to early onset lung cancer, this would only explain a few lung cancer patients with a family history of lung or other cancers. ${ }^{137}$ For example, relatives of retinoblastoma sufferers carrying germ line RB mutation are about 15 times more likely to die from lung cancer than the general population, providing an example of genetic predisposition to lung cancer. ${ }^{138}$ However, more common genetic polymorphisms which occur frequently in the population are more likely to have a larger quantitative effect on the risk of lung cancer. ${ }^{137}$ The carcinogenesis of tobacco smoke is a process that involves activation of procarcinogens that lead to adduct formation and possible failure of DNA repair which should normally remove these adducts, and polymorphisms which affect each of these steps can be inherited. ${ }^{137} \mathrm{~A}$ lot of research has therefore been directed at identifying the more common genetic polymorphisms which could affect the risk of lung cancer, such as those dealing with molecules associated with carcinogen handling and DNA repair. ${ }^{137}$ Studies comparing DNA repair capacity in newly diagnosed lung cancer patients and age matched controls indicate significant differences between the two groups. ${ }^{137}$ Polymorphic variation in the activity of enzymes implicated in the metabolism of tobacco carcinogens include the GST family ${ }^{139}$ and P450 enzymes. ${ }^{140}$ It is therefore likely that individual risk depends on cumulative tobacco exposure and is modified by host genetic differences. Some studies suggest that women have a greater increased risk than men of developing lung cancer following exposure to cigarette smoke carcinogens. ${ }^{141}$ In addition, there is recent evidence from Taiwan that women can develop adenocarcinomas of the lung related to oncogenic human papilloma virus infection. ${ }^{142}$ The ultimate relevance of these molecular epidemiology studies will require careful consideration of the relative role of multiple low penetrant genes in determining individual lung cancer risk and translation of this knowledge to the practical fight against lung cancer. ${ }^{143}$

\section{PRENEOPLASIA AND EARLY DETECTION}

In a multistep fashion, preneoplastic cells somatically accumulate genetic alterations which ultimately progress to invasive cancer by clonal expansion. Morphologically distinct preneoplastic bronchial epithelial changes (hyperplasia, metaplasia, dysplasia, and carcinoma in situ) can be observed before invasive cancer develops and are best described for squamous cell carcinomas. ${ }^{12}{ }^{66}$ Mutations (G-A transversions) in genes such as the p53 gene characteristic of cigarette smoke carcinogens are found not only in lung tumours but also in associated non-tumour lung tissue, indicating specific genetic damage by these carcinogens. ${ }^{144}$ However, other potential premalignant lesions are now implicated: atypical adenomatous hyperplasia as a precursor for peripheral adenocarcinomas and diffuse idiopathic neuroendocrine cell hyperplasia for carcinoids. Analysis of microdissected preneoplastic lesions suggests one model of sequential LOH at chromosome regions $3 p$, then $9 p, 8 p, 17 p$ (with $p 53$ mutation), $5 \mathrm{q}$, and RAS mutations, although it is likely that there is some molecular heterogeneity as exists in overt cancers. ${ }^{12}{ }^{66}{ }^{145-148}$ The genetic changes found in invasive cancers and preneoplasia can also be identified in morphologically normal bronchial epithelium from current or former smokers. ${ }^{11}{ }^{12}{ }^{148-151}$ Some reversal of the morphology can occur after smoking cessation, although the increased risk of lung cancer does not completely return to baseline, raising the possibility of irreversible damage. These observations are consistent with "field cancerisation", whereby the whole tissue region is repeatedly exposed to tobacco smoke and is at risk of developing multiple, separate, clonally unrelated foci of neoplasia, a notion supported by the widespread presence of aneuploidy in the respiratory tree of smokers. ${ }^{152}$ This was confirmed in a study of 195 histologically normal or slightly abnormal epithelium samples and 23 dysplastic epithelium samples from 19 lobectomy specimens where two thirds of the 19 lobectomies had at least one focus of molecularly altered bronchial epithelium. ${ }^{13}$ The findings indicated that multiple small clonal or subclonal patches containing molecular abnormalities are present in normal or slightly abnormal bronchial epithelium of patients with lung cancer.

\section{FUTURE RESEARCH}

How do we exploit this knowledge and the technological advances in, for example, the ability to obtain and test cells and cellular products such as DNA and RNA from sputum, bronchial biopsy specimens, brushing specimens, lavage fluids, and blood? A major challenge is to find a biomarker or panel of markers with sufficient sensitivity and specificity for detecting the variety of lung cancer types, given their molecular heterogeneity. In this regard, acquired hypermethylation changes may be helpful as a panel of biomarkers that will be able to detect abnormalities in most lung cancers. However, a potential biomarker needs not only to be easily detectable in body fluids (that is, sensitive), but it must also be specific for neoplastic transformation and not just reflect smoking related lung damage. Consider, for example, the phenomenon of microsatellite alterations (a PCR method of detecting acquired qualitative and quantitative changes in microsatellite repeat sequences) which have now been found in patients with chronic obstructive pulmonary disease as well as in patients with lung cancer. ${ }^{153}{ }^{154}$ 
Table 1 Clinical use (translation to the clinic) of molecular information in lung cancer

\begin{tabular}{|c|c|}
\hline Issue & Potential approaches \\
\hline $\begin{array}{l}\text { Molecular } \\
\text { epidemiology }\end{array}$ & $\begin{array}{l}\text { Genetic stratification of lung cancer risk; } \\
\text { integratation of this assessment into smoking } \\
\text { cessation treatments, chemoprevention, and } \\
\text { screening trials }\end{array}$ \\
\hline Early detection & $\begin{array}{l}\text { Detection of lung cancer specific genetic and } \\
\text { epigenetic changes in sputum, blood, bronchial } \\
\text { biopsies, brushings, and lavage specimens }\end{array}$ \\
\hline Chemoprevention & $\begin{array}{l}\text { Determination of the genetic and epigenetic } \\
\text { abnormalities in specimens from bronchial } \\
\text { epithelium to use as intermediate biomarkers for } \\
\text { response to chemoprevention and smoking cessation }\end{array}$ \\
\hline Diagnosis & $\begin{array}{l}\text { Use of biomarkers as an adjunct to standard } \\
\text { morphological and histological diagnosis and to } \\
\text { assist in subtype differentiation }\end{array}$ \\
\hline Treatment & $\begin{array}{l}\text { Direct treatment at molecular targets abnormal in } \\
\text { lung cancer but not in normal tissues. These include } \\
\text { inhibitors of oncogenes, growth factors and their } \\
\text { receptors such as tyrosine kinase inhibitors, } \\
\text { farnesyltransferase inhibitors, cyclin dependent } \\
\text { kinase inhibitors, cyclo-oxgenase inhibitors, } \\
\text { antisense molecules, replacement gene therapy to } \\
\text { correct tumour suppressor gene defects, apoptosis } \\
\text { modulators, and inhibitors of angiogenesis and } \\
\text { telomerase. }\end{array}$ \\
\hline Prognosis & $\begin{array}{l}\text { Use of molecular biomarkers to predict outcome } \\
\text { including survival, metastatic potential, and } \\
\text { probability of response to chemotherapy, } \\
\text { radiotherapy or biological treatments }\end{array}$ \\
\hline
\end{tabular}

\section{CONCLUSIONS}

It has been hypothesised that clinically evident lung cancers have accumulated many different genetic or epigenetic abnormalities in oncogenes and/or TSGs. This notion has important clinical ramifications; it should, for instance, be possible to discover carcinogen exposed bronchial epithelial cells with only a subset of these changes and to intervene with very early treatment and/or chemoprevention. The finding of some commonality in the molecular lesions in this heterogeneous group of malignancies recognised histologically as lung cancer is also important, with implications for developing specific diagnostic and therapeutic biotargets, summarised in table 1 . The intrinsic molecular heterogeneity will pose problems for designing global approaches that would be suitable for all lung cancers but, conversely, may provide an insight into how different lung cancer subtypes hijack biological processes in their attempt to evolve and grow. The ability to detect molecular changes in at risk bronchial epithelium may translate into novel intermediate markers for chemoprevention. One of the biggest challenges will be integrating the molecular based strategies such as biomarkers or treatment options with conventional lung cancer management tools; we will need to learn how to exploit early detection biomarkers with modern imaging such as low dose helical CT scanning and targeted treatments with conventional chemotherapy and radiotherapy. ${ }^{155}$ An early example of this is the use of $\beta$-tubulin mutations to predict the response to paclitaxel. ${ }^{156}$ Overall, these translational studies need to link the laboratory with the pulmonary physicians who care for patients with thoracic disease and with those involved in screening trials for lung cancer using, for example, spiral CT scans. ${ }^{157}$ Finally, these studies need to be integrated with investigation of a genetic predisposition to lung cancer arising from polymorphisms in the human population. ${ }^{137} 158$

\section{ACKNOWLEDGEMENTS}

Supported by Lung Cancer SPORE P50 CA70907 and the G Harold and Leila Y Mathers Charitable Foundation.

\section{Authors' affiliations}

K M Fong, The Prince Charles Hospital, Rode Road, Chermside,

Brisbane 4032, Australia

Y Sekido, Department of Clinical Preventive Medicine, Nagoya University School of Medicine, Tsurumai 65, Showa-ku, Nagoya, 466-8560 Japan

A F Gazdar, J D Minna, Hamon Center for Therapeutic Oncology Research, University of Texas Southwestern Medical Center, Dallas, TX 75390-8593, USA

\section{REFERENCES}

1 Jemal A, Thomas A, Murray T, et al. Cancer statistics, 2002. CA Cancer J Clin 2002;52:23-47.

2 Parkin DM, Pisani P, Ferlay J. Global cancer statistics. CA Cancer J Clin 1999:49: 33-64, 2

3 Zochbauer-Muller S, Minna JD. The biology of lung cancer including potential clinical applications. Chest Surg Clin North Am 2000; 10:691-708.

4 Zochbauer-Muller S, Gazdar AF, Minna JD. Molecular pathogenesis of lung cancer. Annu Rev Physiol 2002;64:681-708.

5 Sekido Y, Fong KM, Minna JD. Progress in understanding the molecular pathogenesis of human lung cancer. Biochim Biophys Acta 1998;1378:F21-59.

6 Fong K, Sekido Y, Minna JD. The molecular basis of lung carcinogenesis. In: Coleman WB, Tsongalis G, eds. The molecular basis of human cancer. Totowa, NJ: Humana Press, 2001:379-405.

7 Garber ME, Troyanskaya OG, Schluens K, et al. Diversity of gene expression in adenocarcinoma of the lung. Proc Nat Acad Sci USA 2001;98:13784-9.

8 Bhattachariee A, Richards WG, Staunton J, et al. Classification of human lung carcinomas by mRNA expression profiling reveals distinct adenocarcinoma subclasses. Proc Natl Acad Sci USA 2001;98:13790-5.

9 Hecht SS. Tobacco smoke carcinogens and lung cancer. J Natl Cancer Inst 1999:91:1194-210.

10 Fiore MC, Jorenby DE, Baker TB. Smoking cessation: principles and practice based upon the AHCPR Guideline, 1996. Agency for Health Care Policy and Research. Ann Behav Med 1997; 19:213-9.

11 Wistuba II, Lam S, Behrens C, et al. Molecular damage in the bronchial epithelium of current and former smokers. J Natl Cancer Inst 1997:89:1366-73.

12 Wistuba I, Behrens C, Milchgrub S, et al. Sequential molecular abnormalities are involved in the multistage development of squamous cell lung carcinoma. Oncogene 1999;18:643-50.

13 Park IW, Wistuba, II, Maitra A, et al. Multiple clonal abnormalities in the bronchial epithelium of patients with lung cancer. J Natl Cancer Inst 1999;91:1863-8.

14 Mao L, Lee J, Kurie J, et al. Clonal genetic alterations in the lungs of current and former smokers. J Natl Cancer Inst 1997:89:857-62.

15 Hanahan D, Weinberg RA. The hallmarks of cancer. Cell 2000;100:57-70.

16 Pfeiffer P, Clausen PP, Andersen K, et al. Lack of prognostic significance of epidermal growth factor receptor and the oncoprotein p185HER-2 in patients with systemically untreated non-small-cell lung cancer: an immunohistochemical study on cryosections. Br J Cancer 1996:74:86-91.

17 Rusch V, Baselga J, Cordon-Cardo C, et al. Differential expression of the epidermal growth factor receptor and its ligands in primary non-small cell lung cancers and adjacent benign lung. Cancer Res 1993;53(10 Suppl):2379-85.

18 Rachwal WJ, Bongiorno PF, Orringer MB, et al. Expression and activation of erbB-2 and epidermal growth factor receptor in lung adenocarcinomas. $\mathrm{Br} J$ Cancer 1995;72:56-64.

19 Hsieh ET, Shepherd FA, Tsao MS. Co-expression of epidermal growth factor receptor and transforming growth factor-alpha is independent of ras mutations in lung adenocarcinoma. Lung Cancer 2000;29:151-7.

20 O'Byrne KJ, Cox G, Swinson D, et al. Towards a biological staging model for operable non-small cell lung cancer. Lung Cancer 2001;34(Suppl 2):S83-9.

21 Ohsaki Y, Tanno S, Fujita Y, et al. Epidermal growth factor receptor expression correlates with poor prognosis in non-small cell lung cancer patients with p53 overexpression. Oncol Rep 2000;7:603-7.

22 D'Amico TA, Aloia TA, Moore MB, et al. Molecular biologic substaging of stage I lung cancer according to gender and histology. Ann Thorac Surg $2000 ; 69: 882-6$

23 Cox G, Jones JL, Andi A, et al. A biological staging model for operable nonsmall cell lung cancer. Thorax 2001;56:561-6.

24 Brabender J, Danenberg KD, Metzger R, et al. Epidermal growth factor receptor and HER2-neu mRNA expression in non-small cell lung cancer is correlated with survival. Clin Cancer Res 2001;7:1850-5.

25 Baselga J, Pfister D, Cooper MR, et al. Phase I studies of anti-epidermal growth factor receptor chimeric antibody C225 alone and in combination with cisplatin. J Clin Oncol 2000;18:904-14.

26 Weiner DB, Nordberg J, Robinson R, et al. Expression of the neu geneencoded protein (P185 18 eu in human non-small cell carcinomas of the lung. Cancer Res 1990;50:421-25.

27 Tsai C-M, Chang K-T, Perng R-P, et al. Correlation of intrinsic chemoresistance of non-small-cell lung cancer cell lines with HER-2/neu gene expression but not with ras gene mutations. J Natl Cancer Inst 1993;85:897-901.

28 Yu D, Wang SS, Dulski KM, et al. c-erbB-2/neu overexpression enhances metastatic potential of human lung cancer cells by induction of metastasisassociated properties. Cancer Res 1994;54:3260-6. 
29 Kern JA, Slebos RJ, Top B, et al. C-erbB-2 expression and codon $12 \mathrm{~K}$-ras mutations both predict shortened survival for patients with pulmonary adenocarcinomas. J Clin Invest 1994;93:516-20.

30 Agus DB, Bunn PA, Jr, Franklin W, et al. HER-2/neu as a therapeutic target in non-small cell lung cancer, prostate cancer, and ovarian cancer. Semin Oncol 2000;27(6 Suppl 11):53-63; 92-100.

31 Wang WL, Healy ME, Sattler M, et al. Growth inhibition and modulation of kinase pathways of small cell lung cancer cell lines by the novel tyrosine kinase inhibitor STI 571. Oncogene 2000;19:3521-8.

32 Krystal GW, Hines SJ, Organ CP. Autocrine growth of small cell lung cancer mediated by coexpression of c-kit and stem cell factor. Cancer Res 1996;56:370-6.

33 Krystal GW, Honsawek S, Litz J, et al. The selective tyrosine kinase inhibitor STI571 inhibits small cell lung cancer growth. Clin Cancer Res 2000;6:3319-26.

34 Richardson GE, Johnson BE. The biology of lung cancer. Semin Oncol 1993:20:105-27.

35 Kelley MJ, Linnoila RI, Avis IL, et al. Antitumor activity of a monoclonal antibody directed against gastrin-releasing peptide in patients with small cell lung cancer. Chest 1997;1 12:256-61.

36 Chaudhry A, Carrasquillo JA, Avis IL, et al. Phase I and imaging trial of a monoclonal antibody directed against gastrin-releasing peptide in patients with lung cancer. Clin Cancer Res 1999;5:3385-93.

37 Fathi Z, Way JW, Corjay MH, et al. Bombesin receptor structure and expression in human lung carcinoma cell lines. J Cell Biochem Suppl 1996:24:237-46.

38 Siegfried JM, DeMichele MA, Hunt JD, et al. Expression of mRNA for gastrin-releasing peptide receptor by human bronchial epithelial cells. Association with prolonged tobacco exposure and responsiveness to bombesin-like peptides. Am J Respir Crit Care Med 1997;156:358-66.

39 Shriver SP, Bourdeau HA, Gubish CT, et al. Sex-specific expression of gastrin-releasing peptide receptor: relationship to smoking history and risk of lung cancer. J Natl Cancer Inst 2000;92:24-33.

40 Grimberg A, Cohen P. Role of insulin-like growth factors and their binding proteins in growth control and carcinogenesis. J Cell Physiol 2000;183:1-9.

41 Sueoka N, Lee HY, Wiehle S, et al. Insulin-like growth factor binding protein6 activates programmed cell death in non-small cell lung cancer cells. Oncogene 2000;19:4432-6.

42 Hochscheid R, Jaques G, Wegmann B. Transfection of human insulin-like growth factor-binding protein 3 gene inhibits cell growth and tumorigenicity: a cell culture model for lung cancer. J Endocrinol 2000; 166:553-63.

$43 \mathrm{Wu} X, \mathrm{Yu} \mathrm{H}, \mathrm{Amos} \mathrm{Cl}$, et al. Joint effect of insulin-like growth factors and mutagen sensitivity in lung cancer risk. J Natl Cancer Inst 2000;92:737-43.

44 Slebos RJ, Hruban RH, Dalesio O, et al. Relationship between K-ras oncogene activation and smoking in adenocarcinoma of the human lung. J Natl Cancer Inst 1991;83:1024-7.

45 Greenblatt MS, Bennett WP, Hollstein M, et al. Mutations in the p53 tumor suppressor gene: clues to cancer etiology and molecular pathogenesis. Cancer Res 1994;54:4855-78.

46 Johnson L, Mercer K, Greenbaum D, et al. Somatic activation of the K-ras oncogene causes early onset lung cancer in mice. Nature 2001;410:1111-6.

47 Slebos RJ, Kibbelaar RE, Dalesio O, et al. K-ras oncogene activation as a prognostic marker in adenocarcinoma of the lung. N Engl J Med 1990;323:561-5.

48 Mitsudomi T, Steinberg SM, Oie HK, et al. ras gene mutations in non-small cell lung cancers are associated with shortened survival irrespective of treatment intent. Cancer Res 1991;51:4999-5002.

49 Rosell R, Li S, Skacel Z, et al. Prognostic impact of mutated K-ras gene in surgically resected non-small cell lung cancer patients. Oncogene 1993;8:2407-12.

50 Siegfried JM, Gillespie AT, Mera R, et al. Prognostic value of specific KRAS mutations in lung adenocarcinomas. Cancer Epidemiol Biomarkers Prev 1997:6:841-7.

51 Graziano SL, Gamble GP, Newman NB, et al. Prognostic significance of Kras codon 12 mutations in patients with resected stage I and II non-small-cell lung cancer. J Clin Oncol 1999;17:668-75.

52 Rodenhuis S, Boerrigter L, Top B, et al. Mutational activation of the K-ras oncogene and the effect of chemotherapy in advanced adenocarcinoma of the lung: a prospective study. J Clin Oncol 1997; 15:285-91.

53 Schiller JH, Adak S, Feins RH, et al. Lack of prognostic significance of p53 and $\mathrm{K}$-ras mutations in primary resected non-small-cell lung cancer on E4592: a Laboratory Ancillary Study on an Eastern Cooperative Oncology Group Prospective Randomized Trial of Postoperative Adjuvant Therapy. $J$ Clin Oncol 2001;19:448-57.

54 Kwiatkowski DJ, Harpole DH Jr, Godleski J, et al. Molecular pathologic substaging in 244 stage I non-small-cell lung cancer patients: clinical implications. J Clin Oncol 1998;16:2468-77.

55 Karp JE, Kaufmann SH, Adjei AA, et al. Current status of clinical trials of farnesyltransferase inhibitors. Curr Opin Oncol 2001;13:470-6.

56 Adjei AA. Blocking oncogenic Ras signaling for cancer therapy. J Natl Cancer Inst 2001;93:1062-74.

57 Bernasconi NL, Wormhoudt TA, Laird-Offringa IA. Post-transcriptional deregulation of myc genes in lung cancer cell lines. Am J Respir Cell Mol Biol 2000;23:560-5.

58 Volm M, Koomagi R. Prognostic relevance of c-Myc and caspase-3 for patients with non-small cell lung cancer. Oncol Rep 2000;7:95-8.

59 Kubokura H, Tenjin T, Akiyama H, et al. Relations of the c-myc gene and chromosome 8 in non-small cell lung cancer: analysis by fluorescence in situ hybridization. Ann Thorac Cardiovasc Surg 2001;7:197-203.
60 Ou X, Campau S, Slusher R, et al. Mechanism of all-trans-retinoic acidmediated L-myc gene regulation in small cell lung cancer. Oncogene 1996;13:1893-9.

61 Wistuba II, Gazdar AF, Minna JD. Molecular genetics of small cell lung carcinoma. Semin Oncol 2001;28(2 Suppl 4):3-13.

62 Apolinario RM, van der Valk P, de Jong JS, et al. Prognostic value of the expression of $\mathrm{p} 53, \mathrm{bcl}-2$, and bax oncoproteins, and neovascularization in patients with radically resected non-small-cell lung cancer. J Clin Oncol 1997: 15:2456-66.

63 Brambilla E, Negoescu A, Gazzeri S, et al. Apoptosis-related factors p53, $\mathrm{BCl} 2$, and $\mathrm{Bax}$ in neuroendocrine lung tumors. Am J Pathol 1996; 149:1941-52

64 Bandala E, Espinosa M, Maldonado V, et al. Inhibitor of apoptosis-1 (IAP-1) expression and apoptosis in non-small-cell lung cancer cells exposed to gemcitabine. Biochem Pharmacol 2001;62:13-9.

65 Girard L, Zochbauer-Muller S, Virmani AK, et al. Genome-wide allelotyping of lung cancer identifies new regions of allelic loss, differences between small cell lung cancer and non-small cell lung cancer, and loci clustering. Cancer Res 2000;60:4894-906.

66 Wistuba I, Behrens C, Virmani AK, et al. High resolution chromosome 3p allelotyping of human lung cancer and preneoplastic/preinvasive bronchial epithelium reveals multiple, discontinuous sites of $3 p$ allele loss and three regions of frequent breakpoints. Cancer Res 2000;60:1949-60.

67 Sozzi G, Veronese ML, Negrini M, et al. The FHIT gene 3p14.2 is abnormal in lung cancer. Cell 1996;85:17-26.

68 Fong KM, Biesterveld EJ, Virmani A, et al. FHIT and FRA3B 3p14.2 allele loss are common in lung cancer and preneoplastic bronchial lesions and are associated with cancer-related FHIT cDNA splicing aberrations. Cancer Res 1997; 57:2256-67.

69 Siprashvili Z, Sozzi G, Barnes LD, et al. Replacement of FHIT in cancer cells suppresses tumorigenicity. Proc Natl Acad Sci USA 1997;94:13771-6.

$70 \mathrm{Ji} \mathrm{L}$, Fang B, Yen N, et al. Induction of apoptosis and inhibition of tumorigenicity and tumor growth by adenovirus vector-mediated fragile histidine triad (FHIT) gene overexpression. Cancer Res 1999;59:3333-9.

71 Lerman MI, Minna JD. The 630-kb lung cancer homozygous deletion region on human chromosome 3p21.3: identification and evaluation of the resident candidate tumor suppressor genes. The International Lung Cancer Chromosome 3p21.3 Tumor Suppressor Gene Consortium. Cancer Res 2000;60:6116-33

72 Dammann R, Li C, Yoon JH, et al. Epigenetic inactivation of a RAS association domain family protein from the lung tumour suppressor locus 3p21.3. Nature Genet 2000;25:315-9.

73 Dammann R, Takahashi T, Pfeifer GP. The CpG island of the novel tumor suppressor gene RASSF1A is intensely methylated in primary small cell lung carcinomas. Oncogene 2001;20:3563-7.

74 Burbee DG, Forgacs E, Zochbauer-Muller S, et al. Epigenetic inactivation of RASSF $1 A$ in lung and breast cancers and malignant phenotype suppression. J Natl Cancer Inst 2001;93:691-9.

75 Sekido $Y$, Bader $S$, Latif $F$, et al. Human semaphorins $A(V)$ and IV reside in the $3 p 21.3$ small cell lung cancer deletion region and demonstrate distinct expression patterns. Proc Natl Acad Sci USA 1996;93:4120-5.

76 Kondo M, Ji L, Kamibayashi C, et al. Overexpression of candidate tumor suppressor gene FUS1 isolated from the 3p21.3 homozygous deletion region leads to $\mathrm{Gl}$ arrest and growth inhibition of lung cancer cells. Oncogene $2001 ; 20: 6258-62$

77 Tomizawa Y, Sekido Y, Kondo M, et al. Inhibition of lung cancer cell growth and induction of apoptosis after reexpression of 3 p21.3 candidate tumor suppressor gene SEMA3B. Proc Natl Acad Sci USA 2001 ;98:13954-9.

78 Xian J, Clark KJ, Fordham R, et al. Inadequate lung development and bronchial hyperplasia in mice with a targeted deletion in the Duttl/Robol gene. Proc Natl Acad Sci USA 2001;98:15062-6.

79 Virmani AK, Rathi A, Zochbauer-Muller S, et al. Promoter methylation and silencing of the retinoic acid receptor-beta gene in lung carcinomas. J Natl Cancer Inst 2000:92:1303-7.

80 Geradts J, Fong KM, Zimmerman PV, et al. Correlation of abnormal RB, pl $6^{\text {ink } 4} a$, and $p 53$ expression with $3 p$ loss of heterozygosity, other genetic abnormalities, and clinical features in 103 primary non-small cell lung cancers. Clin Cancer Res 1999:5:791-800.

81 Takahashi T, Nau MM, Chiba I, et al. p53: a frequent target for genetic abnormalities in lung cancer. Science 1989;246:491-4.

82 Bennett WP, Hussain SP, Vahakangas KH, et al. Molecular epidemiology of human cancer risk: gene-environment interactions and p53 mutation spectrum in human lung cancer. J Pathol 1999;187:8-18.

83 Mitsudomi T, Hamajima N, Ogawa M, et al. Prognostic significance of p53 alterations in patients with non-small cell lung cancer: a meta-analysis. Clin Cancer Res 2000:6:4055-63.

84 Kandioler-Eckersberger D, Kappel S, Mittlböck M, et al. The TP53 genotype but not immunohistochemical result is predictive of response to cisplatinbased neoadjuvant therapy in stage III non-small cell lung cancer. J Thorac Cardiovasc Surg 1999; 117:744-50.

85 Matsuzoe D, Hideshima T, Kimura A, et al p53 mutations predict non-small cell lung carcinoma response to radiotherapy. Cancer Lett 1999; 135: 189-94

86 Laudanski J, Niklinska W, Burzykowski T, et al. Prognostic significance of p53 and bcl-2 abnormalities in operable nonsmall cell lung cancer. Eur Respir J 2001;17:660-6.

87 Roth JA, Grammer SF, Swisher SG, et al. Gene therapy approaches for the management of non-small cell lung cancer. Semin Oncol 2001;28/4 Suppl 14):50-6.

88 Schuler M, Herrmann R, De Greve JL, et al. Adenovirus-mediated wild-type p53 gene transfer in patients receiving chemotherapy for advanced 
non-small-cell lung cancer: results of a multicenter phase II study. J Clin Oncol 2001;19:1750-8.

89 Higashiyama M, Doi O, Kodama K, et al. MDM2 gene amplification and expression in non-small-cell lung cancer: immunohistochemical expression of its protein is a favourable prognostic marker in patients without p53 protein accumulation. Br J Cancer 1997;75:1302-8.

90 Reissmann PT, Koga H, Takahashi R, et al. Inactivation of the retinoblastoma susceptibility gene in non-small-cell lung cancer. The Lung Cancer Study Group. Oncogene 1993:8:1913-9.

91 Cagle PT, El-Naggar AK, Xu H-J, et al. Differential retinoblastoma protein expression in neuroendocrine tumors of the lung. Potential diagnostic implications. Am J Pathol 1997; 150:393-400.

92 Dosaka-Akita H, Hu S-X, Fujino M, et al. Altered retinoblastoma protein expression in nonsmall cell lung cancer: its synergistic effects with altered ras and p53 protein status on prognosis. Cancer 1997;79:1329-37.

93 Ookawa K, Shiseki $M$, Takahashi $R$, et al. Reconstitution of the RB gene suppresses the growth of small-cell lung carcinoma cells carrying multiple genetic alterations. Oncogene 1993;8:2175-81.

94 Betticher DC, Heighway J, Hasleton PS, et al. Prognostic significance of CCNDI (cyclin D1) overexpression in primary resected non-small-cell lung cancer. Br J Cancer 1996;73:294-300.

95 Caputi M, De Luca L, Papaccio G, et al. Prognostic role of cyclin D1 in non small cell lung cancer: an immunohistochemical analysis. Eur J Histochem 1997;41:133-8.

96 Driscoll B, Wu L, Buckley S, et al. Cyclin DI antisense RNA destabilizes pRb and retards lung cancer cell growth. Am J Physiol 1997;273(5 Pt 1):L941-9.

97 Lingfei K, Pingzhang $Y$, Zhengguo $L$, et al. A study on p16, pRb, cdk4 and cyclinD1 expression in non-small cell lung cancers. Cancer Lett 1998;130:93-101.

98 Shapiro GI, Supko JG, Patterson A, et al. A phase II trial of the cyclindependent kinase inhibitor flavopiridol in patients with previously untreated stage IV non-small cell lung cancer. Clin Cancer Res 2001;7:1590-9.

99 Virmani AK, Rathi A, Sathyanarayana UG, et al. Aberrant methylation of the adenomatous polyposis coli (APC) gene promoter 1A in breast and lung carcinomas. Clin Cancer Res 2001;7:1998-2004.

100 Zochbauer-Muller S, Fong KM, Virmani AK, et al. Aberrant promoter methylation of multiple genes in non-small cell lung cancers. Cancer Res 2001;61:249-55.

101 Zochbauer-Muller S, Fong KM, Maitra A, et al. 5' $\mathrm{CpG}$ island methylation of the FHIT gene is correlated with loss of gene expression in lung and breast cancer. Cancer Res 2001;61:3581-5.

102 Merlo A, Herman JG, Mao L, ef al. 5' $\mathrm{CpG}$ island methylation is associated with transcriptional silencing of the tumour suppressor p16/CDKN2/MTS1 in human cancers. Nature Med 1995;1:686-92.

103 Otterson GA, Khleif SN, Chen W, et al. CDKN2 gene silencing in lung cancer by DNA hypermethylation and kinetics of p16 $16^{\mathrm{NK} 4}$ protein induction by 5-aza 2' deoxycytidine. Oncogene 1995;11:1211-6.

104 Belinsky SA, Nikula KJ, Palmisano WA, et al. Aberrant methylation of pl6(INKa) is an early event in lung cancer and a potential biomarker for early diagnosis. Proc Natl Acad Sci USA 1998;95:11891-6.

105 Kim DH, Nelson HH, Wiencke JK, et al. Promoter methylation of DAP-kinase: association with advanced stage in non-small cell lung cancer. Oncogene 2001;20:1765-70

106 Makos M, Nelkin BD, Lerman Ml, et al. Distinct hypermethylation patterns occur at altered chromosome loci in human lung and colon cancer. Proc Natl Acad Sci U A 1992:89:1929-33.

107 Kohno T, Kawanishi M, Inazawa J, et al. Identification of CpG islands hypermethylated in human lung cancer by the arbitrarily primed-PCR method. Hum Genet 1998;102(3).

108 Soria JC, Rodriguez M, Liu DD, et al. Aberrant promoter methylation of multiple genes in bronchial brush samples from former cigarette smokers. Cancer Res 2002;62:351-5.

109 Palmisano WA, Divine KK, Saccomanno G, et al. Predicting lung cancer by detecting aberrant promoter methylation in sputum. Cancer Res 2000;60:5954-8.

110 Esteller M, Sanchez-Cespedes M, Rosell R, et al. Detection of aberrant promoter hypermethylation of tumor suppressor genes in serum DNA from non-small cell lung cancer patients. Cancer Res 1999:59:67-70.

111 Zhu WG, Dai Z, Ding H, et al. Increased expression of unmethylated CDKN2D by 5-aza-2'-deoxycytidine in human lung cancer cells. Oncogene 2001;20:7787-96.

112 Hiyama K, Hiyama E, Ishioka S, et al. Telomerase activity in small-cell and non-small-cell lung cancers. J Natl Cancer Inst 1995;87:895-902.

113 Albanell J, Lonardo F, Rusch V, et al. High telomerase activity in primary lung cancers: association with increased cell proliferation rates and advanced pathologic stage. J Natl Cancer Inst 1997:89:1609-15.

114 Arinaga M, Shimizu S, Gotoh K, et al. Expression of human telomerase subunit genes in primary lung cancer and its clinical significance. Ann Thorac Surg 2000;70:401-6.

115 Yashima K, Litzky LA, Kaiser L, et al. Telomerase expression in respiratory epithelium during the multistage pathogenesis of lung carcinomas. Cancer Res 1997:57:2373-7.

116 Xinarianos G, Scott FM, Liloglou T, et al. Evaluation of telomerase activity in bronchial lavage as a potential diagnostic marker for malignant lung disease. Lung Cancer 2000;28:37-42.

117 Hara H, Yamashita K, Shinada J, et al. Clinicopathologic significance of telomerase activity and hTERT mRNA expression in non-small cell lung cancer. Lung Cancer 2001;34:219-26.

118 White LK, Wright WE, Shay JW. Telomerase inhibitors. Trends Biotechno 2001;19:114-20.
119 Angeletti CA, Lucchi M, Fontanini G, et al. Prognostic significance of tumoral angiogenesis in completely resected late stage lung carcinoma (stage IIIAN2). Impact of adjuvant therapies in a subset of patients at high risk of recurrence. Cancer 1996;78:409-15.

120 Fontanini G, Lucchi M, Vignati S, et al. Angiogenesis as a prognostic indicator of survival in non-small-cell lung carcinoma: a prospective study. $J$ Natl Cancer Inst 1997;89:881-6.

121 Pastorino U, Andreola S, Tagliabue E, et al. Immunocytochemical markers in stage I lung cancer: relevance to prognosis. J Clin Oncol 1997:15:2858-65.

122 Offersen BV, Pfeiffer P, Hamilton-Dutoit S, et al. Patterns of angiogenesis in nonsmall-cell lung carcinoma. Cancer 2001;91:1500-9.

123 Yuan A, Yu CJ, Kuo SH, et al. Vascular endothelial growth factor 189 mRNA isoform expression specifically correlates with tumor angiogenesis, patient survival, and postoperative relapse in non-small-cell lung cancer. J Clin Oncol 2001; 19:432-41.

124 O'Byrne KJ', Koukourakis MI, Giatromanolaki A, et al. Vascular endothelial growth factor, platelet-derived endothelial cell growth factor and angiogenesis in non-small-cell lung cancer. Br J Cancer 2000;82. $1427-32$.

125 Mattern J, Koomagi R, Volm M. Association of vascular endothelial growth factor expression with intratumoral microvessel density and tumour cell proliferation in human epidermoid lung carcinoma. $\mathrm{Br} J$ Cancer 1996:73:931-4.

126 Fontanini G, Vignati S, Lucchi M, et al. Neoangiogenesis and p53 protein in lung cancer: their prognostic role and their relation with vascular endothelia growth factor (VEGF) expression. Br J Cancer 1997;75:1295-301.

127 Niklinska W, Burzykowski T, Chyczewski L, et al. Expression of vascular endothelial growth factor (VEGF) in non-small cell lung cancer (NSCLC): association with p53 gene mutation and prognosis. Lung Cancer 2001;34(Suppl 2):S59-64.

128 Tamura M, Ohta Y, Kajita T, et al. Plasma VEGF concentration can predic the tumor angiogenic capacity in non-small cell lung cancer. Oncol Rep 2001;8:1097-102.

129 D'Amico TA, Aloia TA, Moore MB, et al. Predicting the sites of metastases from lung cancer using molecular biologic markers. Ann Thorac Surg 2001:72:1144-8.

130 Shih JY, Yang SC, Hong TM, et al. Collapsin response mediator protein-1 and the invasion and metastasis of cancer cells. J Natl Cancer Inst $2001 ; 93: 1392-400$

131 Akashi $\mathrm{T}$, Ito E, Eishi $Y$, et al. Reduced expression of laminin alpha 3 and alpha 5 chains in non-small cell lung cancers. Jpn J Cancer Res 2001;92:293-301.

132 Manda R, Kohno T, Niki T, et al. Differential expression of the LAMB3 and LAMC2 genes between small cell and non-small cell lung carcinomas. Biochem Biophys Res Commun 2000;275:440-5.

133 Moriya Y, Niki T, Yamada T, et al. Increased expression of laminin-5 and its prognostic significance in lung adenocarcinomas of small size. An immunohistochemical analysis of 102 cases. Cancer 2001;91: $1129-41$.

134 Carmelli D, Swan GE, Robinette D, et al. Genetic influence on smoking: a study of male twins. N Engl J Med 1992;327:829-33.

135 Heath AC, Madden PA, Slutske WS, et al. Personality and the inheritance of smoking behavior: a genetic perspective. Behav Genet 1995;25:103-17.

136 Arinami T, Ishiguro H, Onaivi ES. Polymorphisms in genes involved in neurotransmission in relation to smoking. Eur J Pharmacol 2000;410:215-26.

137 Amos $\mathrm{Cl}, \mathrm{Xu}$ W, Spitz MR. Is there a genetic basis for lung cancer susceptibility? Recent Results Cancer Res 1999;151:3-12.

138 Sanders BM, Jay M, Draper GJ, et al. Non-ocular cancer in relatives of retinoblastoma patients. Br J Cancer 1989;60:358-65.

139 Reszka E, Wasowicz W. Significance of genetic polymorphisms in glutathione S-transferase multigene family and lung cancer risk. Int $J$ Occup Med Environ Health 2001;14:99-113.

140 Wolf CR, Smith CA, Forman D. Metabolic polymorphisms in carcinogen metabolising enzymes and cancer susceptibility. Br Med Bull 1994;50:718-31.

141 Zang EA, Wynder EL. Differences in lung cancer risk between men and women: examination of the evidence. J Natl Cancer Inst 1996;88 183-92.

142 Cheng YW, Chiou HL, Sheu GT, et al. The association of human papillomavirus $16 / 18$ infection with lung cancer among nonsmoking Taiwanese women. Cancer Res 2001:61:2799-803.

143 Vineis P, Schulte P, McMichael AJ. Misconceptions about the use of genetic tests in populations. Lancet 2001;357:709-12.

144 Hussain SP, Amstad P, Raja K, et al. Mutability of p53 hotspot codons to benzo(a)pyrene diol epoxide (BPDE) and the frequency of p53 mutations in nontumorous human lung. Cancer Res 2001:61:6350-5.

145 Hung J, Kishimoto Y, Sugio K, et al. Allele-specific chromosome 3p deletions occur at an early stage in the pathogenesis of lung carcinoma. JAMA 1995;273:558-63.

146 Kishimoto Y, Sugio K, Hung JY, et al. Allele-specific loss in chromosome 9p loci in preneoplastic lesions accompanying non-small-cell lung cancers (see comments). J Natl Cancer Inst 1995;87:1224-9.

147 Sugio $K$, Kishimoto $Y$, Virmani AK, et al. K-ras mutations are a relatively late event in the pathogenesis of lung carcinomas. Cancer Res 1994;54: $5811-5$.

148 Wistuba II, Gazdar AF. Molecular abnormalities in the sequential development of lung carcinoma. In: Sivastava S, Henson DE, Gazdar AF, eds. Molecular pathology of early cancer. IOS Press, 1999:265-76.

149 Wistuba II, Behrens C, Virmani AK, et al. High resolution chromosome 3p allelotyping of human lung cancer and preneoplastic/preinvasive bronchial 
epithelium reveals multiple, discontinuous sites of $3 p$ allele loss and three regions of frequent breakpoints. Cancer Res 2000;60 1949-60.

150 Wistuba II, Berry J, Behrens C, et al. Molecular changes in the bronchial epithelium of patients with small cell lung cancer. Clin Cancer Res 2000;6:2604-10.

151 Mao L, Lee JS, Kurie JM, et al. Clonal genetic alterations in the lungs of current and former smokers (see comments). J Natl Cancer Inst 1997:89:857-62.

152 Smith AL, Hung J, Walker L, et al. Extensive areas of aneuploidy are present in the respiratory epithelium of lung cancer patients. $\mathrm{Br} J$ Cancer 1996;73:203-9.

153 Siafakas NM, Tzortzaki EG, Sourvinos G, et al. Microsatellite DNA instability in COPD. Chest 1999;116:47-51.
154 Field JK, Liloglou T, Xinarianos G, et al. Genetic alterations in bronchial lavage as a potential marker for individuals with a high risk of developing lung cancer. Cancer Res 1999;59:2690-5.

155 Adjei AA, Haluska P, Dy GK. Novel pharmacological agents in clinical development for solid tumours. Expert Opin Investig Drugs 2001;10:2059-88.

156 Rosell R, Felip E. Predicting response to paclitaxel/carboplatin-based therapy in non-small cell lung cancer. Semin Oncol 2001;28(4 Supp 14):37-44.

157 Henschke Cl, McCauley DI, Yankelevitz DF, et al. Early Lung Cancer Action Project: overall design and findings from baseline screening. Lancet 1999;354:99-105.

158 Williams MD, Sandler AB. The epidemiology of lung cancer. Cancer Treat Res 2001;105:31-52.

\title{
LUNG ALERT
}

\section{Airway stents provide symptomatic relief}

$\Delta$ Wood DE, Liu $Y$, Vallières $E$, et al. Airway stenting for malignant and benign tracheobronchial stenosis. Ann Thorac Surg 2003;76:167-74

\begin{abstract}
T
his paper reports the indications, techniques, and results of tracheobronchial stenting in the authors' unit. One hundred and forty three patients underwent 309 stent procedures

between May 1992 and December 2001. Malignancy was the most common indication ( $67 \%$ of cases). The main symptoms were dyspnoea, respiratory distress, and stridor. $82 \%$ of patients required emergency procedures as most (77\%) had more than $75 \%$ narrowing of the airway. All patients underwent rigid bronchoscopies except two who had flexible bronchoscopies for insertion of expandable metal stents. $87 \%$ of stents placed were silicone rubber. $27 \%$ of patients had primarily a tracheal obstruction but in $49 \%$ multiple sites were involved.15\% required multiple stents and $68 \%$ had a bronchoscopic intervention (core out, dilatation, brachytherapy, laser or photodynamic therapy) in preparation or as an adjunct to stenting. Significant improvement was reported in $95 \%$ of patients; $41 \%$ required multiple bronchoscopies to maintain this improvement. Complications from stenting occurred in $41 \%$ of cases-namely, stent migration, partial occlusion of stent by secretions, and partial obstruction by granulations. Perforation occurred in four patients but only one required thoracotomy. $28 \%$ of patients with malignancy required further intervention to maintain airway patency (mean airway palliation 4 months). $45 \%$ of patients with malignant disease and $17 \%$ with benign disease had no follow up data available following the original intervention.

This paper shows that stenting can produce immediate symptomatic improvement in unresectable patients but multiple stents and procedures are frequently required.
\end{abstract}

P Macedo

Ealing Hospital, UK ; patmac@doctors.org.uk 